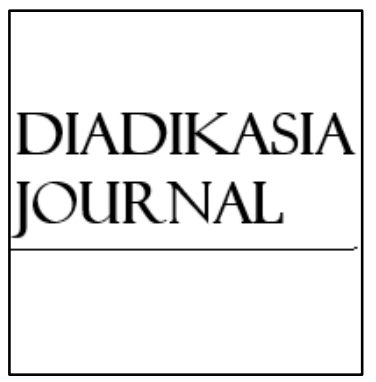

Diadikasia Journal

ISSN: $2721-9070$

Copyright $\odot 2020$ Diadikasia Organization

https://diadikasia.pubpub.org/

Volume 1(1): 39-49

DOI: $10.21428 / 8 c 841009.6403$ bo6b

\title{
ADVERTORIALS FOR VOCATIONAL SENIOR SECONDARY SCHOOL (VSSS) IN INDONESIA: A MULTIMODAL ANALYSIS
}

\author{
Ema Wilianti Dewi \\ emawiliantidewi@gmail.com \\ UPT PBB IAIN Syekh Nurjati \\ Jl. Perjuangan, Cirebon, Indonesia 45131
}

\section{Ayu Meiratnasari}

ayumeiratnasari@student.uns.ac.id

Universitas Sebelas Maret

Jl. Ir. Sutami No. 36A, Surakarta, Indonesia 57126

\begin{abstract}
This paper analyses four advertorial texts about phone product in the magazines. Advertorials provide the new-image advertisement into promotion activity. It reflects a strong multimodality. The practice of multimodality becomes the new trends that attract the attention of people. A multimodal analysis was chosen since the practice of multimodality surrounds the texts. However, the focus discussion in this paper is the visual semiotic systems that are reflected in the texts. This paper brings the results of the analysis to classroom practice, mainly to teach the brand new promoting agents to the vocational senior secondary school in Indonesia.
\end{abstract}

Keywords: Advertorial, Multimodality, English teaching, Vocational senior secondary schools.

\section{Introduction}

The Indonesian government has been realized the importance of vocational education by providing those programme since senior high school level which named by Sekolah Menengah Kejuruan (SMK) or vocational senior secondary schools (VSSS). Based on data centre and statistics education and culture of Indonesian education and culture ministry (2017), there are 3.434 of VSSS in Indonesia. Each country will have different purpose of their vocational education programme.

Thomson (1973) stated “... Vocational education can develop a marketable man by developing his ability to perform skills that extend his utility as a tool of production". It means that vocational education is developed to sell decent humans by developing their 
skills in performance skills as a means of production. It seems to link with the aims of Indonesian vocational programmed, which has the objectives such as follows, Dikmenjur (2008): (1) entering employment and developing a professional attitude. (2) Able to choose a career, compete and develop them. (3) become a middle-level workforce to fill the needs of the business world/industry world today and the future. (4) Being a productive, adaptive and creative workforce.

To achieve the aims, the Indonesian government has some strategies. First, the government arranged the subjects in vocational education program under the curriculum. Those kinds of arrangement are expected the people who deal with the flow of globalization and issues related to environmental issues, technological advances and information, the rise of the creative and cultural industries, and the development of education at the international level. The flow of globalization will shift the lifestyle of society from agrarian and traditional commerce to modern industrial and commerce society as can be seen in World Trade Organization (WTO), Association of Southeast Asian Nations (ASEAN) Community, Asia-Pacific Economic Cooperation (APEC) and ASEAN Free Trade Area (AFTA) (Permendikbud, 2013). It means that vocational education does not just organize the students to be a creative workforce. However, they can be creative entrepreneurs who can involve in the modern industrial and commercial.

Second, the government place English as required subjects not only for vocational education but also for the other education level. However, the English subject for senior high school and VSSS are different. In the VSSS, the English subject is based on English for specific purpose (ESP). Basturkmen (2006) stated in ESP, "Language is learnt not for its own sake or for the sake of gaining a general education, but to smooth the path to entry or greater linguistic efficiency in academic, professional or workplace environments". It describes that the language learning can be arranged based on the needs of the learners. LAMRI (2016) said that "the ESP teacher has to develop materials which present as clearly as possible useful area of the language so that learners can perceive the relation between the content of the course and their requirements". It means that the teachers in the ESP are permitted to organize their materials after analyzing the needs of the students.

Considering vocational education is related to the business world, it shows that the students of vocational education should have marketing skill after they are graduated. So, the students seem to learn some kinds of advertisement tool while they assail their vocational education. In this case, the researchers consider advertorial as one of material to encourage the student's marketing skill, especially for the students in the marketing program. In the previous study, the result of the research done by Golan (2014), who uses advertorial as a tool in diplomacy mediation showed that advertorial could shape and influence public opinion. So, the researchers are curious about to what extent advertorial can be implemented in the educational field. Based on the background above, this research aims to investigate: (1) how does the advertorial text become the attractive marketing agents to persuade the customers to buy the product through visual 
components within multimodal construction? (2) How to apply the advertorial to the vocational senior secondary school (VSSS)?

To accomplish the objectives of the research, there are four advertorial texts of phone product will be analyzed by the researchers using multimodal analysis. Multimodal analysis sees the text as one of the communication mode that is available for social interaction. Kress and Leeuwen (1996) argue that multimodal discourse analysis is the new reality in a semiotic landscape, particularly the thing that carries by socio and cultural factors; those are the intensification of language and cultural variety.

\section{Literature Review}

Vocational education is a form of education which aims to the attainment of education related to a particular job (Kotsikis, 2007). It is also defined as one appealing way to deal with these evolution problems is to link students more closely to jobs through vocational education programs and internships with a firm (Ryan, 2001; Zimmerman et al., 2013). Moodie (2008) define vocational education and training as 'the development and application of knowledge and skills for middle-level occupations needed by society from time to time'. VET takes many forms and is perhaps the least unitary of education sectors. It contributed to individuals' development and had a range of distinct educational purposes not addressed by other education sectors. In its contemporary forms in many countries, it also has the most significant potential to engage the broadest range of learners within its programmed, institutions and experiences (Billett, 2011).

As mentioned in the background of the study that the Indonesian government seats English as required subject start from junior high school to university put English as specific purpose (ESP) is adapted for Indonesia vocational education program. Hutchinson and Waters (1987) define that ESP is an approach to language learning, and it is based on learners' need. What they mean is that ESP does not involve a particular kind of language, teaching material or methodology. Robinson, (1991) ESP is usually goaldirected and that ESP courses develop from a needs analysis, which aims to specify as carefully as possible what exactly it is that students have to do through the medium of English. ESP has traditionally been divided into two classified main branches such as English for Academic Purposes or EAP and English for Occupational Purposes or EOP (Hutchinson and Waters, 1987; Howatt, 1984; Strevens, 1980; Robinson, 1991; DudleyEvans \& St. John, 1998). EAP (English for Academic Purposes) refers to any English teaching that relates to academic study needs (Robinson, 1991; Dudley-Evans \& St. John, 1998). Then, according to Robinson (1991), EOP (English for Occupational Purposes) involves work-related needs and training. Dudley-Evans \& St. John (1998) elucidate EOP includes professional purposes in administration, medicine, law and business, and vocational purposes for non-professionals in work or pre-work situations. 
Since vocational education relates to business, it means that the students of vocational education should be able to be a marketer. In this case, advertorial can be seen as one of useful tool to promote something. Sonderman and Tran (2013) said that advertorials seek to present advertisement as editorial content and let the reader know about the brand involvement. It is still not very transparent in all the magazines. However, they see also that advertorials borrow the credibility of editorial content, and indeed, advertorials are the oldest form of content marketing. Van Reijmersdal et al. (2005) note that advertorials' typeface and layout mimic the magazine's editorial style where the advertorial is placed. Stout et al. (1989) make a similar definition of advertorial as "those advertiser paid blocks that combine identifiable advertising with simulated editorial text." Andersson (1995) says "advertorials, like commercial copy, are designed to camouflage their commercial identity and capitalize on the public's trust in journalistic integrity" (Cohen 2010).

\section{Methods}

The multimodal analysis is chosen as the methodology of this research. Halliday (1978) argued that the development of multimodal analysis was arising from systemic functional linguistics that seen the language in the perspective of doing things and making meaning. This method is used since the source of this research is the advertorial text that combined the visual and aural semiotic systems. The subject of this study was four selected advertorial texts from online resources.

\section{Discussion}

\section{A. Samsung Advertorials: A Multimodal Discourse Analysis}

The main objective of an advertorial is to bring the new-image of advertisement to the promotion markets. Despite its typical news-like appearance, advertorial focuses on a product's positive characteristics and represent an oversimplified viewpoint on the phone, mainly the Samsung product. In order to present and transfer as much information to the consumers as possible in a society where visual culture has become increasingly important, advertorial has brought the commercial advertisement from single-mode to multimodal expression of advertising.

The part primarily discussed the visual components of Samsung advertorial to have a more precise understanding of how the advertorial deals with the consumer through multimodal construction while propagating its set value.

\section{Representational meaning}

Moreover, Van Leeuwen (2006) revealed that the patterns of participants represent their class, structure, and meaning. Here, narrative patterns serve to present unfolding actions and events, processes of change, transitory spatial arrangements. 


\section{(1) Narrative Process}

Process is classified into three sub-processes: action processes, reaction processes, and verbal and mental processes. Action process occurred when the Actor is the leading participant. When images or diagrams have only one participant, this participant is usually an Actor; the resulting structure is non-transactional process. The Actor, in whole or in part, forms the vector, which can be analyzed through size, place in the composition, contrast against the background, colour saturation or conspicuousness, sharpness of focus, and through the 'psychological salience' which individual participants have for viewers (Kress \& van Leeuwen, 2006, p. 63).

In the Samsung advertorials, transactional processes overweigh non-transactional ones, especially when it comes to the construction of the highlights in each scene where salient Actors are shown correctly 'aimed at' the Goal, creating a concrete context to the viewer who, in this case, is saved the trouble of needing to ponder over the profound meanings behind. However, non-transactional processes do exist, and the occasional appearance is not randomly arranged or edited, on the contrary, the process usually appears at the early stage of a scene with the gesture of represented participant forming a vector without specific Goal in the frame, forming an open-ended situation for consideration, and leaving the viewer imagining the psychological activities of the Actor, in other words, relating to the image, thus creating a sense of empathy or identification.

Reactional processes, the vector is formed by an eye line, the direction of the glance of one or more of the represented participants (Kress \& van Leeuwen, 2006, p. 67). The Reactor, the participant who does the looking, is the girl in the Samsung advertorial, she did not appear all the body. However, it represents the way she used the phone interpretatively. The Phenomena may be formed either by another participant or a visual proposition and when there is no Phenomenon, reactions are non-transactional. The function of the Phenomena is essential for the advertorial in that it forms the transactional reaction, which is quite prominent in the recreational processes and presents the concrete and easy-to-comprehend imagery to the viewer to enhance the validity and legitimacy of the product. In verbal and mental processes, a special kind of vector, in the form of thought balloons and dialogue balloons that connect drawings of speakers or thinkers to their speech or thought, is discussed for its appearance in comic strips. However, the vector does not appear in the advertorial. Thus the discussion of verbal and mental process is omitted from the analysis.

(2) Conceptual Process

Conceptual representation is comprised of classificational processes, analytical processes and symbolic processes. The symbolic processes, which discuss the meaning of participants, can be divided into Symbolic Suggestive and Symbolic Attributive depending on whether there exist one or two participants, respectively. The symbolic process is ubiquitous in the Samsung advertorial, and Symbolic Attributive appears more frequently. 
Figure 1.a girl with her phone and stylus

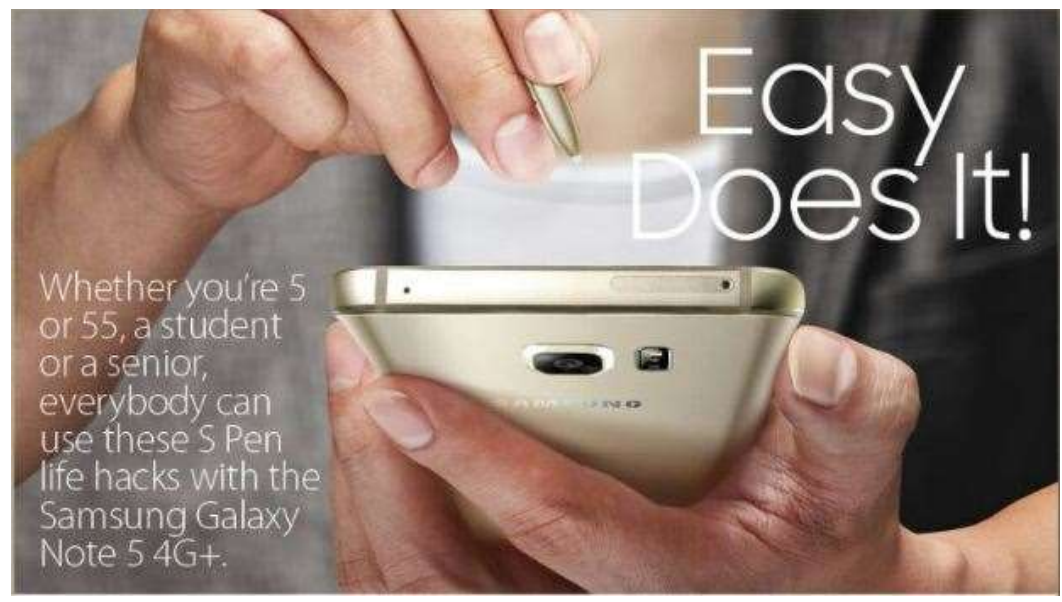

Take one scene as a representative example, in the advertorial, a girl with her phone and stylus (Figure 1), which resemble the shape of phone, pen, camera, etc., is presented. The girl in the background, as a represented participant, is made salient through its size in the picture, and the phone in the middle are visualized source of mental void. With the voice-over says "Easy does it!", the girl holding the pen make the statement that it is easy to use the phone and the pen displays a sense of yearning and fulfilment after the void is completed. Through this multimodal gesture, the equivalence between mental void and unsatisfied material need is constructed by the advertorial, which provides a solution for achieving fulfilment through the quickest wayconsumption.

\section{Interactive Meaning}

Interactive dimension of images is the "writing" of what is usually called "nonverbal communication", a "language" shared by producers and viewers alike. It involves two kinds of participants, represented participants (the people, the places and things depicted in images) and interactive participants (the people who communicate with each other through images, the producers and viewers of images), and three kinds of relations: (1) relations between represented participants; (2) relations between interactive and represented participants (the interactive participants' attitudes towards the represented participants); and (3) relations between interactive participants (the things interactive participants do to or for each other through images) (Kress \& van Leeuwen, 2006, p.114). The interactive meaning is realized by four factors: contact, social distance, attitude and modality.

\section{(1) Contact}

Visual configuration has two related functions. On the one hand, an image may create a visual form of direct address, in which contact is established by direct eye gaze or gestures of represented participants, in this case, we call this kind of image a 'demand'; on the other hand, an image may also address the viewer indirectly, in this case, it 'offers' the represented participants to the viewer as items of information, 
objects of contemplation, impersonally, as though they were specimens in a display case (Kress \& van Leeuwen, 2006, p. 119).

The Samsung advertorial, 'offer' images are presented. The represented participants, women, do not create direct eye contact with viewers. The intangible yet undeniable link between happiness and consumption is strongly indicated to the viewers. What the ad offers for its viewers is the sense of fulfilment people gained from buying the commodities they wanted, which insinuates that the viewers can also feel satisfied and live a happier life mimicking what the represented participants do, in other words, buying Samsung phones.

(2) Social Distance

Choice of distance can suggest different relations between represented participants and viewers; the construction of the image itself can make the viewer feel close or far away from the represented participant. In our daily interactive activities, the regulation imposed on social relation and interaction determines the distance we should keep from each other and influences the way we interact with each other.

Advertorial, size of frame is invariably defined about the human body. According to Kress and van Leeuwen, the close shot (close personal distance) shows the head and shoulders of the subject, and the very close shot (intimate distance) anything less than that. The medium close shot (far personal distance) cuts off the subject at the waist, the medium shot (close social distance) approximately at the knees. The medium-long shot (far social distance) shows the full figure. In the long shot (free distance) the human figure occupies about half the height of the frame, and the very long shot is anything 'wider' than that (Kress \& van Leeuwen, 2006, pp. 124-125). In conclusion, the distance of depicted participants from the viewer is one of the material realizations of social interaction in a given context.

(3) Attitude

Discusses the relations between represented participants and the viewer, and the system of perspective realizes "attitude", which is often socially determined, is usually realized by the selection of the angle. The selection of an angle, a 'point of view', implies the possibility of expressing subjective attitudes towards represented participants, human or otherwise (Kress \& van Leeuwen, 2006, p.129).

Angle forms either a frontal or a tipping point of view, which respectively signifies different degree of involvement or detachment. Represented participant shown by frontal angle indicates that special attention needs to be paid to him or her, participants are shown by oblique angle; on the other hand, usually suggests otherwise. In the Samsung advertorial, a frontal angle is widely used in the construction of images so that the audience has a more excellent feeling of being involved in the high specification phone atmosphere.

(4) Modality

Term 'modality' comes from linguistics and refers to the truth value or credibility of (linguistic realized) statements about the world (Kress \& van Leeuwen, 2006, p. 155). The 
specific degrees of modality are measured by modality markers including colour saturation, differentiation and modulation, contextualization, representation, depth, illumination and brightness. In the Tmall ad, full-colour saturation, highly diversified range of colours and fully modulated colour are prominent, displaying articulated and detailed background, low degree of abstraction and high brightness value. By presenting an ad with the features above, a light-hearted and cheerful atmosphere is presented, echoing with the theme of the festival. The detailed depiction, along with a sense of approval created by the positive atmosphere, helps to justify consumption willfully on this very day.

\section{Compositional Meaning}

Relates the representational and interactive meaning of the image to each other through three interrelated systems (Kress \& van Leeuwen, 2006, p. 177): information value, salience and framing.

(1) Information Value

Placement of elements (participants and syntagms that relate them to each other and the viewer) endows them with the specific informational values attached to the various 'zones' of the image: left and right, top and centre and margin (Kress \& van Leeuwen, 2006, p. 177). The left to right composition shows the information from given to new, top to bottom shows the information from ideal to real, and centre and margin composition signifies the greater emphasis on the central part of images.

The Samsung advertorial, most page follow the centre and margin construction in which the represented participants are usually the highlighted part in images. The central composition is relatively uncommon in contemporary Western visualization, in any case. According to Kress and van Leeuwen, perhaps it is the greater emphasis on hierarchy, harmony and continuity in Confucian thinking that makes centring a fundamental organizational principle in the visual semiotic of Asian culture (Kress \& van Leeuwen, 2006, p. 195).

\section{B. Teaching Advertorials in Vocational School}

English nowadays has a considerable influence to the educational area. In Indonesia, English exists in both formal school and informal school. The need for English as a foreign language in Indonesia is different for each school. The formal school, for example, use English in different context and function. In advance school, in this case, senior high school and vocational high school have different need of English.

Norland (2006) as cited in Kristina (2018) revealed the steps in the ESP approach for classroom activity, those are

1) Doing need analysis from field and profession where the students will have an occupation. 
2) From the need analysis, planning the activity where the students will use English in their field.

3) It involves both micro-linguistics aspects such as vocabulary and language structure and macro-linguistics aspects such as discourse and specific rhetorical pattern that uses in the field and student's occupation.

The teaching strategy that can make the advertorial applied come as follows:

1) The teachers encourage students to tell about their everyday life and listen to it carefully.

2) The teachers facilitate open discussion to encourage students to tell the story appropriate with their interest.

3) The teachers observe and help the students to find and decide on the topic that exciting for them.

4) The teachers show pictures and stories, as an illustration, to help the students decide the purpose of choosing that topic.

5) The students make a small group and discuss the project that they need to do.

6) The students plan the project related to the actual issue around them.

From the need analysis, this kind of text was designed to be taught to the SMK students. It is expected that the SMK students, particularly the Marketing major, will know the vocabulary and convention of text that is corresponding to their major. The lesson that will be attributed to this text is online marketing. The teaching rules will be as follows:

1) Students are put in a small group

2) The teacher share the material both using PPT and hard copy

3) The students are told about the objective of the lesson, which is focused on the text and the visual display

4) The students encourage identifying the text and making a list of the publication, headlines, opening, the body, and the closing. The students also encourage finding out the tricky word and making a list then finding the meaning.

5) The students are expected to grasp the structure and the message of the text

6) Each group will discuss the structure and the message

7) The students are given opportunities to practice presentation using the technical words on the text

8) A teacher tells the student that each member of the group takes a similar responsibility to present the idea

9) The representative of the groups present the idea in turn in front of the class

10) The teacher encourages them to explain by using $5 \mathrm{~W}+1 \mathrm{H}$

11) The students make collaboration with other groups by asking or providing ideas and opinion

12) The students are assigned to find an advertorial text on their own with different themes and present their views about it in class

Teachers can use this kind of assignment for their students. 
1) Discuss with your group about the findings, take some note of the idea, and decide one product to be promoted.

2) Assign a group representative to present the idea in front of the class

3) Write a simple advertorial text based on your product

\section{Conclusion}

It can be concluded that the visual semiotic system of advertorials can be the tools to make a new image advertisement. The combination from multimodality in the advertorials gives the advertorial a strong point to persuade the customers. To teaching a second language in the Indonesian context, advertorials are the new term of advertisement for promoting products and help the VSSS (SMK) students do promotion activity within the marketing subject.

\section{References}

Amiryousefi, M., \& Dastjerdi, H. V. (2010). Vocabulary: Challenges and Debates. English Language Teaching, 3(3), 89-94.

Aronson, J. 1995. A pragmatic view of thematic analysis. The Qualitative Report, 2 (1). Retrieved 30.4.2015 from http://www.nova.edu/ssss/QR/Backlssues/QR2-1/aronson.html

Belcher, D. D., \& Connor, U. (Eds.). (2001). Reflections on multiliterate lives (Vol. 26). Multilingual Matters.

Braun, V., Clarke, V., Hayfield, N., \& Terry, G. (2019). Thematic analysis. Handbook of research methods in health social sciences, 843-860.

Cohen, E.L. 2002. Online journalism as market-driven journalism. Journal of broadcasting \& Electronic media, 46 (4), 532-548.

Dewi, E. W., Drajati, N. A., \& Yunus, M. M. (2019). Exploring Intonations in Sesame Street's Puppet Shows: A Phonological Perspective. Issues in Language Studies, 8(2), 32-47.

Dewi, E. W., Nurkamto, J., \& Drajati, N. A. (2019). Exploring Peer-Assessment Practice in Graduate Students'academic Writing. LLT Journal: A Journal on Language and Language Teaching, 22(1), 58-65.

Dudley-Evans, T. \& ST John M. J. 1998. Developments in English for specific purposes. Cambridge: Cambridge University Press.

Erjavec, K. \& Kovacec, M.P. 2010. Relations with the media: Who are the main actors in an advertorial process in Slovenia? Journalism 11(1), 91-109.

Fattah, N. (2019). Landasan manajemen pendidikan.

Habibi, H. (2018). Protecting National Identity Based On The Value Of Nation Local Wisdom. International Journal of Malay-Nusantara Studies, 1(2), 24-40.

Habibi, H. (2016). Peran Ki Dalang Basari (1950-2003) dalam Perkembangan Islam di Gegesik Cirebon. Jurnal Tamaddun: Jurnal Sejarah dan Kebudayaan Islam, 1(2).

Halliday, M. (1994). An Introduction to Functional Grammar. London: Edward Arnold (Publishers) Limited.

Hastings, R., \& Pennington, W. (2019). Team Coaching: A thematic analysis of methods used by external coaches in a work domain. International Journal of Evidence Based Coaching and Mentoring, 17(2), 174-188.

Hofer, A. R., Hanick, S. L., \& Townsend, L. (2018). Transforming information literacy instruction: Threshold concepts in theory and practice. ABC-CLIO.

Howatt A. P. R. 1984. A history of English language teaching. Oxford: Oxford University Press. 
Hutchinson T \& Waters A. 1987. English for specific purposes. New York: Cambridge University Press.

King, N., \& Brooks, J. (2018). Thematic analysis in organisational research. The SAGE handbook of qualitative business and management research methods: methods and challenges.

Kress, G., \& van Leeuwen, T. (2006). Reading Images: The Grammar of Visual Design (2nd ed.). London: Routledge.

Robinson P. 1991. ESP today: A practitioner's guide. New York: Prentice Hall.

Sari, L. I., \& Soetopo, D. (2017). The Complexity of the Language Level and the Multimodality Used in Singaporean and Indonesian Science Textbooks Written in English for Primary Three and Four. English Education Journal, 7(3), 255-261.

Stout, P. A., Wilcox, G. B., \& Greer , L. S.1989. Trend in magazine advertorial use.Journalism Quarterly, 66(4), 960.

Strevens P. 1980. Teaching English as an international language. Oxford: Pergamon Press Ltd.

Van Reijmersdal, E., Neijens, P. \& Smit, E. 2005. Readers' Reactions to Mix-tures of Advertising and Editorial Content in Magazines. Journal of Current Issues \& Research in Advertising (CTC Press) 27 (2), 39-53.

Vaismoradi, M., Jones, J., Turunen, H., \& Snelgrove, S. (2016). Theme development in qualitative content analysis and thematic analysis.

Cite: Dewi, E. W., \& Meiratnasari, A. (2020). Advertorials for Vocational Senior Secondary School (VSSS) in Indonesia: A Multimodal Analysis. Diadikasia Journal, 1(1), 39-49. https://doi.org/10.21428/8c841009.6403bo6b 